\title{
ATP puts the brake on DNA double-strand break repair
}

A new study shows that ATP switches the Mre11-Rad50-Nbs1 repair factor between signaling and processing of DNA ends

Karl-Peter Hopfner ${ }^{12}$

${ }^{1}$ Department of Biochemistry and

${ }^{2}$ Center for Integrated Protein Science Munich

at the Gene Center

Ludwig-Maximilians-University

Munich, Germany

Contact details:

Prof. Dr. Karl-Peter Hopfner

Gene Center

Feodor-Lynen-Str. 25

81377 Munich, Germany

email: hopfner@genzentrum.Imu.de

Web: http://hopfner.genzentrum.Imu.de

Tel. +49 (0) 89218076953

Fax. +49 (0) 89218076999 


\section{Summary}

DNA double-strand breaks (DSBs) are one of the most deleterious forms of DNA damage and can result in cell inviability or chromosomal aberrations. The Mre11-Rad50-Nbs1 (MRN) ATPase-nuclease complex is a central player in the cellular response to DSBs and is implicated in the sensing and nucleolytic processing of DSBs, as well as in DSBs signaling by activating the cell cycle checkpoint kinase ATM. ATP binding to Rad50 switches MRN from an open state with exposed Mre11 nuclease sites to a closed state with partially buried nuclease sites. The functional meaning of this switch remained unclear. A new study shows that ATP binding to Rad50 promotes DSB recognition, tethering and ATM activation, while ATP hydrolysis opens the nuclease active sites to promote processing of DSBs. MRN thus emerges as functional switch that may coordinate the temporal transition from signaling to processing of DSBs.

Abbreviations:

$\begin{array}{ll}\text { 53BP1 } & \text { p53 binding protein 1 } \\ \text { ABC } & \text { ATP binding cassette } \\ \text { ATM } & \text { Ataxia telangiectasia-mutated protein kinase } \\ \text { ATR } & \text { ATM and Rad3-related protein kinase } \\ \text { BRCA1 } & \text { Breast cancer 1, early onset } \\ \text { BRCA2 } & \text { Breast cancer 2, early onset } \\ \text { CtIP } & \text { CtBP interacting protein } \\ \text { DDR } & \text { DNA damage response } \\ \text { DSB } & \text { DNA double-strand break } \\ \text { H2AX } & \text { Histone 2AX } \\ \text { HDR } & \text { Homology directed repair } \\ \text { Mre11 } & \text { Meiotic recombination gene 11 } \\ \text { MRN } & \text { Mre11-Rad50-Nbs1 } \\ \text { MMEJ } & \text { Microhomology mediated end joining } \\ \text { NBD } & \text { Nucleotide binding domain } \\ \text { NBS1 } & \text { Nijmegen breakage syndrome 1 } \\ \text { NHEJ } & \text { Non-homologous end joining } \\ \text { Rad50 } & \text { Radiation gene 50 } \\ \text { Rad51 } & \text { Radiation gene 51 } \\ \text { SAE2 } & \text { Sporulation in the Absence of Spo Eleven 2 } \\ \text { XRS2 } & \text { X-ray sensitivity 2 }\end{array}$




\section{Introduction}

DNA double-strand breaks (DSBs) threaten genomic integrity in all domains of life. DSBs arise during genome replication and can be induced by ionizing radiation, topoisomerase poisons and genotoxic chemicals. Furthermore, programmed DSBs are important intermediates in the generation of genetic diversity during meiosis and the rearrangements of immunoglobulin loci in the B- and T-cell development.

DSB formation is intimately connected to cancer development. Two prominent breast cancer susceptibility genes, breast cancer associated (BRCA) 1 and $2[1,2]$, are involved in the repair of DSBs. Inactivation of many other DSB signaling and repair factors leads to human disease syndromes such as Bloom's Syndrome [3], Ataxia telangiectasia [4] and Nijmegen breakage syndrome [5]. Patients are predisposed to cancer, but also display to varying extents neurodegeneration, developmental problems and immune deficiencies [6].

Two principal types of repair mechanisms repair DSBs. End joining is a template independent ligation reactions of the two ends. In the "canonical" nonhomologous end joining (NHEJ) reaction, the DNA ends are bound by Ku and ligated by Ligase IV and associated factors. In alternative non-homologous end joining pathways (alt-NHEJ), Ku is eventually removed from DNA ends in a process that requires the MRN complex (see below) and the DNA ends are resected to a limited extent and often joined at microhomologies (denoted then as microhomology mediated end joining (MMEJ)) (for a recent review, see e.g. [7]). The homology directed repair mechanism (HDR), on the other hand, uses the sister chromatid (or the homologous chromosome in meiosis) as a template, resulting in an accurate restoration of the genetic information. The DNA ends are long-range resected and the resulting 3' single-stranded tails are paired with the homologous region in the sister-chromatid (or homologous chromosome in meiosis). The paired 3' tail serves as the primer for template DNA synthesis and accurate restoration of the disrupted genetic information.

It became evident in recent years that the choice of repair pathways - in particular in mammals - is not random but regulated in a cell cycle dependent manner (for a review, see e.g. [8]). The fast but potentially mutagenic end-joining pathway - due to misrecombination or limited processing of DNA ends - is the preferred mode of repair in G1 phase and in human cells also in G2 phase. The accurate HDR is preferred in the $S$ phase as well as for the repair of meiotic DSBs, 
where NHEJ is actively suppressed [9]. The pathway choice is determined in part by mediator proteins. 53BP1 is a mediator in mammalian cells and localizes to chromatin at DSBs, preventing DNA resection and promoting repair by NHEJ [10]. BRCA1 opposes the binding of 53BP1 in S-phase and promotes repair by HDR [11].

In eukaryotic cells, DSBs elicit a complex DNA damage response (DDR) that delays the cell cycle, activates transcriptional responses, results in alterations of the chromatin at the damage sites, activates the particular DSB repair pathway and depending on the damage load - induces apoptosis [12]. The DDR is triggered by activation of the kinases ATM (Ataxia telangiectasia mutated) and ATR (ATM and Rad3 related). ATM is activated in response to ionizing radiation (which is believed to cause DSBs directly or by generating free radicals through the radiolysis of water [13]) [14-16] while ATR is activated by replication protein A coated single-stranded (ss)DNA (e.g. from UV induced replication fork stalling) [17]. ATM and ATR phosphorylate more than 700 target proteins in human cells [18], including histone 2AX (resulting in $\gamma-\mathrm{H} 2 \mathrm{AX}$ ) [19,20], DNA repair factors and checkpoint mediators, cell cycle regulators and kinases, and the stress response transcription factor p53 [21].

Although ATM can be activated also by oxidative stress [22] and alterations in chromatin structure [23], a key factor for the DSBs dependent activation of ATM is the Mre11-Rad50-Nbs1 (MRN) complex [24-32]. MRN recruits ATM to DSBs but is also a substrate of ATM and functions both up- and downstream of ATM $[14,15]$. Besides ATM activation, MRN is also implicated in the structural tethering of DSBs and the processing of DNA ends by means of an endo-/exonuclease function, generating DNA ends that can be repaired by MMEJ or HDR (Fig. 1). The structural and enzymatic roles of MRN in the signaling and repair of DSBs are only partly understood at the mechanistic level. A new study now reveals how different ATPinduced conformational states of MRN regulate DNA tethering, ATM activation, and DNA processing [33].

\section{The Mre11-Rad50-Nbs1 Complex}

Mre11 and Rad50 polypeptides are found in all phylogenetic kingdoms and even in some phages [34], identifying these proteins as an ancient component of the replication/recombination machinery, while Nbs1 (also denoted Xrs2 in Saccharomyces cerevisiae) is only found in eukaryotes [5,35]. MRN (or Mre11Rad50-Xrs2) participates in HDR [36,37], end joining [38-42], meiotic recombination [43-46], and telomere maintenance [42,47-49]. It is also implicated in class switch 
recombination in B-cells [50-53] and the detection of cytosolic DNA, which often arises from pathogen invasion $[54,55]$.

MRN integrates both structural as well as enzymatic functions at DSBs. As an early factor at DSBs [56] it is implicated in the structural tethering of DNA and telomeres [57-61], in the initial nucleolytic processing of DNA ends [39,62], and in the recruitment and activation of ATM [63,64] (Fig. 1).

MRN's ATP-regulated nuclease activity is rather unusual. MRN degrades dsDNA in 3'->5' direction in vitro [65-68] but this activity would generate 5' singlestrand overhangs at DNA ends. In vivo, DNA ends are likely protected from this activity by Ku [69-71] or by Rad51/BRCA2 [72,73]. MRN and its prokaryotic homologs, however, also have endonuclease $[74,75]$ as well as hairpin opening activities [76]. The endonuclease activity is primarily observed at obstructed DNA ends $[65,74,75]$ near the DSBs in vitro and in vivo [74,77-80]. This endonucleolytic cleavage also requires CtIP (denoted SAE2 in S. cerevisiae and Ctp1 in S. pombe), which is specifically activated in S and G2 phases and contributes to the pathway choice [81-84]. Sae2/CtIP is an endonuclease itself and cleaves near hairpin structures that are opened by MRN $[85,86]$. The initially processed DNA ends are repaired by MMEJ or are further resected by Exo1 or BLM and DNA2 and repaired by HDR.

MRN can, however, also nick the DNA at some considerable distance from the DSB followed by $3^{\prime}-5$ ' resection towards the DNA ends $[87,88]$. This is an intriguing model for explaining why MRN possesses both endo- and 3'-5' exonuclease activities. Of note, if the two DNA strands were cut in a random fashion, MRN would in $50 \%$ of the cases degrade DNA away from the break. It is still unclear how the sites for the endonucleolytic cut are chosen several hundred base pairs away from the DSB. Given MRN's ability to open hairpin structures $[66,68,85,86,89]$, the involvement of the bacterial homologs in degrading hairpin structures at replication forks [89], and S. cerevisiae Mre11's binding preference for G-quadruplex DNA in vitro [90], hairpins could play a role.

While further work is required to unravel the precise modes of MRN's and CtIP's nuclease activities at DSBs, the endonuclease activities are well suited to clear obstructed DNA ends, for instance by removing covalently bound Spo11 at meiotic breaks [91] or covalently bound poisoned topoisomerases [92-95]. Perhaps most importantly, the NHEJ factor Ku [96] has a very high affinity for DNA ends and needs to be removed from DNA ends by MRN/CtIP prior to HDR or MMEJ [69,71].

In summary, MRN/CtIP is a highly regulated nuclease system that can clear blocked DNA ends prior to MMEJ or HDR. 


\section{Functional Architecture of MRN}

MRN has an intriguing bipolar architecture with a globular ATP- and DNA-binding "head" and two long coiled-coil "tails". A model that integrates results from different structural approaches is shown in Fig. 2, [33,57,66,67,97-109].

MRN and its related bacterial SbcCD and archaeal MR complexes possess a conserved Mre $11_{2}$-Rad50 ${ }_{2}$ core. In eukaryotes, this core assembles with one or two polypeptides of Nbs1. Mre11 links all three different proteins of the complex together in a highly flexible structure $[100,105,110]$. Mre11 dimer formation is critical for its activity $[102,103,111]$. Rad50 is a fairly large polypeptide that possesses a signature $30-50 \mathrm{~nm}$ long coiled-coil domain $[57,98,99]$. On one end of the coiled-coil is the nucleotide-binding domain (NBD), while on the other end is the $\mathrm{Zn}^{2+}{ }^{2+}$ hook dimerization motif (Fig. 2). Upon binding to ATP, the two NBDs of the Mre11 2 -Rad50 complex engage by sandwiching two ATP molecules in their interface [97]. In the presence of ATP, the NBD dimer binds into the DNA binding cleft of the Mre11 dimer and partially blocks the nuclease active site $[101,105]$. Biochemical studies suggest that in this conformation, the processive exonuclease activity of Mre11 is inhibited, while the endonuclease activity is unaffected $[65,105,112]$. It remains unclear how DNA interacts with MRN in this ATP-bound conformation. On one hand, ATP blocks the dsDNA-binding site of Mre11, yet ATP-binding is also critical for DNA binding by Rad50. Recent single molecule studies suggest that MRN can substantially melt DNA ends in the presence of ATP [113]. The active site in the ATP-bound closed conformation of MRN is perhaps still accessible to ssDNA and might allow endonucleolytic cleavage. Nevertheless, it remains unclear how DNA interacts with the MRN complex in the ATP-bound closed conformation and the nature of the endonuclease activity, especially in DNA duplexes, needs to be determined.

The hook motif joins the coiled-coil domains of two Rad50 polypeptides from the same MRN complex or from different complexes, depending on MRN's interaction with DNA [107]. Both the coiled-coil as well as the hook are essential for the cellular function of the MRN complex $[59,114]$. Studies with murine MRN suggested that the hook is important for ATM dependent activation of the DDR [115]. The ATM activation capability of hook mutants of Rad50 can, however, be rescued by overexpression, suggesting that the coiled-coil domains might ensure an appropriate local concentration of MRN at DSBs [116]. Of note, the coiled-coil domains of Rad50 are fairly conserved in length within, but not across, phylogenetic kingdoms. Reducing the length of the Rad50 coiled-coil abolishes Mre11-Rad50- 
Xrs2 function in S. cerevisiae [114]. This result is remarkable, considering that prokaryotes and bacteriophages naturally contain much shorter coiled-coil domains. Thus, much remains to be learned about the functional role of the coiled-coil domains of Rad50.

Nbs1 (or Xrs2) is responsible for nuclear localization of the complex [117] and contains a variety of protein-protein interaction modules (Fig. 2). The N-terminus, which is truncated or mutated in Nijmegen breakage syndrome [5], possesses a forkhead associated (FHA) domain, in addition to a tandem breast cancer associated C-terminal (BRCT) domain, both of which bind phosphorylated repair or checkpoint factors[104,108]. The C-terminal part of Nbs1 contains Mre11- and ATM-binding motifs $[29,63,117]$. Nbs1 binds across the Mre11 dimer opposite to Mre11's DNA and Rad50 interaction sites, apparently breaking the symmetry of the Mre11-Rad50 complex [102]. It is not yet clear whether these motifs are just attachment sites to recruit ATM to MRN or, alternatively, whether interactions with ATM or Mre11 are linked to the activation of ATM's kinase. MRN can directly stimulate the kinase activity of ATM in vitro in the presence of DNA [64]. The C-terminus of Nbs1 is, however, important for activation of apoptosis in mice by mediating phosphorylation of pro-apoptotic factors by ATM [118], while mutations in the $\mathrm{N}$-terminus of Nbs1 interfere with checkpoint activation as seen in cells from NBS patients. These data suggest that full activation of ATM requires multiple regions of the Nbs1 polypeptide.

\section{ATP triggers conformational changes in Mre11-Rad50 and regulates the nuclease activity}

The distinct structurally-derived ATP-induced conformational states of MRN raise the important question of whether different nucleotide states of MRN possess different cellular functions. Some NTPases, such as small GTPases and associated factors are indeed nucleotide regulated molecular switches, where GTP and GDP states are intrinsically stable and have different functions and interaction partners. For many other NTPases, such as ATP-dependent helicases, the ATP state can be very transient and is part of a single functional cycle that e.g. moves the helicase along DNA.

MRN has a rather slow ATPase activity, suggesting it does not function as a molecular machine but more as a molecular switch. Indeed, a recent study reported that ATM activation by MRN required ATP binding, but not ATP hydrolysis by Rad50 in vitro [116]. In contrast, the Mre11 nuclease activity (but not the Mre11 protein) is 
dispensable for ATM activation, suggesting that a specific ATP-induced conformation of MRN triggers ATM activation.

A new report has now extended this analysis through looking for ATPtriggered separation of function effects in different in vitro and in vivo assays [33]. Prior structural analyses have shown that ATP triggers two types of conformational changes in the Rad50 NBDs. ATP changes the conformation of the NBD itself by rotating one lobe of the ABC type ATPase fold with respect to the other [97]. This rotation properly positions ATP binding motifs to allow, in a second conformational change, the engagement of the two NBDs through sandwiching two ATP molecules in their interface (Fig. 2).

Tanya Paull, John Tainer and colleagues determined high-resolution structures of archaeal Rad50 and noticed that ATP-induced conformational changes go hand in hand with an extensive rearrangement of the hydrogen bonding network, as well as with the filling of structural cavities in the protein [33]. The authors designed mutants to stabilize either one or the other conformational state of Rad50, e.g. by filling a cavity with a bulky residue in order to freeze the conformational state. In vitro, these mutations displayed a several-fold increased or decreased ATP hydrolysis rate, consistent with the design intention. This clever approach allowed the authors to analyze the underlying alleles and mutant proteins in different biochemical and cellular contexts.

By using an in vitro plasmid ligation assay, Desphande et al. showed with archaeal MR that the tethering of DNA ends is largely a function of Rad50 and its coiled-coil domains, although Mre11 can also achieve tethering at much higher concentrations. Rad50 dimers can possibly bind to two DNA ends simultaneously or, alternatively, higher-order complexes could bring DNA ends into closer proximity. Interestingly, mutants that promote the ATP-bound closed conformation of Rad50 exhibit a higher degree of tethering activity. Either increased DNA binding by ATPRad50 together with hook-mediated higher-order complex formation can bring DNA ends together or a single ATP-Rad50 dimer can bind two DNA ends simultaneously. While ATP binding to archaeal MR promotes the tethering of DNA in ligation assays, the opposite is true for the resection activity $[65,105]$. Here, disengagement of the two Rad50 domains by ATP hydrolysis is necessary, presumably to open Mre11's active sites so that they may engage in exonuclease activity.

The authors went on to address the effect of Rad50 mutations in different assays in vivo. Significantly, the mutation that stabilizes the ATP-bound form of MRN grows poorly in the presence of a topoisomerase poison (suggesting a DNA processing defect) but appears to be hyperactive in an end-joining assay with clean 
breaks generated by an endonuclease. Finally, Desphande et al. addressed the signaling functions of the complex and measured $\mathrm{H} 2 \mathrm{~A}$ phosphorylation after ionizing radiation. Interestingly, both mutations that impair ATP-induced Rad50 dimer formation or increase ATP hydrolysis in vitro - and thus destabilize the ATP-bound state - severely affected S. pombe MRN's ability to activate Tel1 (the ATM homolog) in vivo.

In this regard, MRN shares interesting qualities with the general family of $A B C$ proteins to which Rad50 belongs. $A B C$ transporters have both switch- and molecular machine-like properties. They can transport ligands across gradients (energy converting molecular machine) but are often tightly regulated and allosterically activated by the correct ligand (switch). Notably, although MRN and its prokaryotic homologs have a rather poor ATP hydrolysis activity, consistent with them acting as switches, the ATPase of the prokaryotic homologs can be considerably (up to 20 fold) activated by dsDNA in vitro $[65,105]$. Whether this is also true for the eukaryotic complex and whether the activity is subject to further regulation by e.g. Nbs1 or ATM needs to be addressed in future studies.

\section{Conclusions and Outlook}

The new data reveal that the different ATP-regulated structural states of MRN can be functionally separated in a living cell and promote different aspects of the DDR and the DSB repair (Fig. 3). This implies that the ATP-bound state of Rad50 has a sufficiently long lifetime to participate in different biochemical pathways. To better understand the regulation of this state we need to move from a qualitative to a more quantitative analysis of MRN in living cells or more complete biochemical systems.

Although the identification of MRN's ATP-bound form as necessary for ATM activation is an important step forward, several questions remain. The two state model of "open" and "closed" MRN is too simple. If this were true, a signature motif mutant, which prevents formation of the closed state, would also stimulate resection and inhibit ATM activation. Such a mutation, however, behaves like a Rad50 null [119], showing that the ATP-bound closed form of MRN is also critical in HDR.

Furthermore, we lack a molecular model for the tethering functions of the complex, which likely involves formation of supramolecular aggregates $[58,60,107]$. To this end, it will be necessary to provide a more detailed analysis of the interactions of MRN - in particular of Rad50 - with DNA, which remain uncharacterised. This analysis should also help to unravel how DNA end recognition, 
unwinding and endonuclease reactions are achieved in the ATP-bound conformation of MRN, considering that Rad50 blocks Mre11's dsDNA-binding sites in this form.

In summary, while MRN emerges as an ATP-controlled functional switch at DSBs that may coordinate the temporal transition from signaling and tethering to the processing of DSBs, further studies are necessary to provide an overarching mechanistic framework for this key DSB repair factor.

\section{Acknowledgements}

I thank Florian Seifert for generating the coiled-coil model of Mre11-Rad50 in Fig. 2 and Robert Byrne for comments on the manuscript. Work on DNA double-strand break repair in my laboratory is funded by an Advanced Investigator Grant of the European Research Council (ATMMACHINE) and by programs from the German Excellence Initiative (Center for Integrated Protein Sciences Munich (CIPSM) and Quantitative Biosciences Munich (QBM)).

\section{References:}

1 Sharan SK, Morimatsu M, Albrecht U, Lim DS, et al. 1997. Embryonic lethality and radiation hypersensitivity mediated by Rad51 in mice lacking Brca2. Nature 386: 804-10.

2 Scully R, Chen J, Plug A, Xiao Y, et al. 1997. Association of BRCA1 with Rad51 in mitotic and meiotic cells. Cell 88: 265-75.

3 Ellis NA, Groden J, Ye TZ, Straughen J, et al. 1995. The Bloom's syndrome gene product is homologous to RecQ helicases. Cell 83: 655-66.

$4 \quad$ Shiloh Y, Ziv Y. 2013. The ATM protein kinase: regulating the cellular response to genotoxic stress, and more. Nat Rev Mol Cell Biol 14: 197-210.

$5 \quad$ Carney JP, Maser RS, Olivares H, Davis EM, et al. 1998. The hMre11/hRad50 protein complex and Nijmegen breakage syndrome: linkage of double-strand break repair to the cellular DNA damage response. Cell 93: 477-86.

6 Petrini JH. 2000. The Mre11 complex and ATM: collaborating to navigate S phase. Curr Opin Cell Biol 12: 293-6.

7 Chiruvella KK, Liang Z, Wilson TE. 2013. Repair of double-strand breaks by end joining. Cold Spring Harb Perspect Biol 5: a012757.

8 Chapman JR, Taylor MRG, Boulton SJ. 2012. Playing the End Game: DNA Double-Strand Break Repair Pathway Choice. Molecular Cell 47: 497-510.

9 Joyce EF, Paul A, Chen KE, Tanneti N, et al. 2012. Multiple barriers to nonhomologous DNA end joining during meiosis in Drosophila. Genetics 191: $739-46$. 
10 Bunting SF, Callen E, Wong N, Chen HT, et al. 2010. 53BP1 inhibits homologous recombination in Brca1-deficient cells by blocking resection of DNA breaks. Cell 141: 243-54.

11 Chapman JR, Sossick AJ, Boulton SJ, Jackson SP. 2012. BRCA1associated exclusion of 53BP1 from DNA damage sites underlies temporal control of DNA repair. J Cell Sci 125: 3529-34.

12 Harper JW, Elledge SJ. 2007. The DNA damage response: ten years after. Mol Cell 28: 739-45.

13 Jeggo P, Lavin MF. 2009. Cellular radiosensitivity: how much better do we understand it? Int J Radiat Biol 85: 1061-81.

14 Gatei M, Young D, Cerosaletti KM, Desai-Mehta A, et al. 2000. ATMdependent phosphorylation of nibrin in response to radiation exposure. Nat Genet 25: 115-9.

15 Lim DS, Kim ST, Xu B, Maser RS, et al. 2000. ATM phosphorylates p95/nbs1 in an S-phase checkpoint pathway. Nature 404: 613-7.

16 Savitsky K, Bar-Shira A, Gilad S, Rotman G, et al. 1995. A single ataxia telangiectasia gene with a product similar to PI-3 kinase. Science 268: 1749-53.

17 Zou L, Elledge SJ. 2003. Sensing DNA damage through ATRIP recognition of RPA-ssDNA complexes. Science 300: 1542-8.

18 Matsuoka S, Ballif BA, Smogorzewska A, McDonald ER, 3rd, et al. 2007. ATM and ATR substrate analysis reveals extensive protein networks responsive to DNA damage. Science 316: 1160-6.

19 Burma S, Chen BP, Murphy M, Kurimasa A, et al. 2001. ATM phosphorylates histone H2AX in response to DNA double-strand breaks. J Biol Chem 276: 42462-7.

20 Ward IM, Chen J. 2001. Histone H2AX is phosphorylated in an ATRdependent manner in response to replicational stress. J Biol Chem 276: 47759-62.

21 Lakin ND, Hann BC, Jackson SP. 1999. The ataxia-telangiectasia related protein ATR mediates DNA-dependent phosphorylation of p53. Oncogene 18: 3989-95.

22 Guo Z, Kozlov S, Lavin MF, Person MD, et al. 2010. ATM activation by oxidative stress. Science 330: 517-21.

23 Kanu N, Behrens A. 2007. ATMIN defines an NBS1-independent pathway of ATM signalling. EMBO J 26: 2933-41.

24 Carson CT, Schwartz RA, Stracker TH, Lilley CE, et al. 2003. The Mre11 complex is required for ATM activation and the G2/M checkpoint. EMBOJ 22: 6610-20.

25 Nakada D, Matsumoto K, Sugimoto K. 2003. ATM-related Tel1 associates with double-strand breaks through an Xrs2-dependent mechanism. Genes Dev 17: 1957-62.

26 Lee JH, Paull TT. 2004. Direct activation of the ATM protein kinase by the Mre11/Rad50/Nbs1 complex. Science 304: 93-6.

27 Difilippantonio S, Celeste A, Fernandez-Capetillo 0, Chen HT, et al. 2005. Role of Nbs1 in the activation of the Atm kinase revealed in humanized mouse models. Nat Cell Biol 7: 675-85.

28 Morales M, Theunissen JW, Kim CF, Kitagawa R, et al. 2005. The Rad50S allele promotes ATM-dependent DNA damage responses and 
suppresses ATM deficiency: implications for the Mre11 complex as a DNA damage sensor. Genes Dev 19: 3043-54.

29 You Z, Chahwan C, Bailis J, Hunter T, et al. 2005. ATM activation and its recruitment to damaged DNA require binding to the $\mathrm{C}$ terminus of $\mathrm{Nbs1}$. Mol Cell Biol 25: 5363-79.

30 Dupre A, Boyer-Chatenet L, Gautier J. 2006. Two-step activation of ATM by DNA and the Mre11-Rad50-Nbs1 complex. Nat Struct Mol Biol 13: 4517.

31 Berkovich E, Monnat RJ, Jr., Kastan MB. 2007. Roles of ATM and NBS1 in chromatin structure modulation and DNA double-strand break repair. Nat Cell Biol 9: 683-90.

32 Usui T, Ogawa H, Petrini JH. 2001. A DNA damage response pathway controlled by Tel1 and the Mre11 complex. Mol Cell 7: 1255-66.

33 Deshpande RA, Williams GJ, Limbo 0, Williams RS, et al. 2014. ATPdriven Rad50 conformations regulate DNA tethering, end resection, and ATM checkpoint signaling. EMBO J.

34 Almond JR, Stohr BA, Panigrahi AK, Albrecht DW, et al. 2013. Coordination and Processing of DNA Ends During Double-Strand Break Repair: The Role of the Bacteriophage T4 Mre11/Rad50 (MR) Complex. Genetics.

35 Varon R, Vissinga C, Platzer M, Cerosaletti KM, et al. 1998. Nibrin, a novel DNA double-strand break repair protein, is mutated in Nijmegen breakage syndrome. Cell 93: 467-76.

36 Tauchi H, Kobayashi J, Morishima K, van Gent DC, et al. 2002. Nbs1 is essential for DNA repair by homologous recombination in higher vertebrate cells. Nature 420: 93-8.

37 Furuse M, Nagase Y, Tsubouchi H, Murakami-Murofushi K, et al. 1998. Distinct roles of two separable in vitro activities of yeast Mre11 in mitotic and meiotic recombination. EMBO J 17: 6412-25.

38 Moore JK, Haber JE. 1996. Cell cycle and genetic requirements of two pathways of nonhomologous end-joining repair of double-strand breaks in Saccharomyces cerevisiae. Mol Cell Biol 16: 2164-73.

39 Ma JL, Kim EM, Haber JE, Lee SE. 2003. Yeast Mre11 and Rad1 proteins define a $\mathrm{Ku}$-independent mechanism to repair double-strand breaks lacking overlapping end sequences. Mol Cell Biol 23: 8820-8.

40 Rass E, Grabarz A, Plo I, Gautier J, et al. 2009. Role of Mre11 in chromosomal nonhomologous end joining in mammalian cells. Nat Struct Mol Biol 16: 819-24.

41 Xie A, Kwok A, Scully R. 2009. Role of mammalian Mre11 in classical and alternative nonhomologous end joining. Nat Struct Mol Biol 16: 814-8.

42 Boulton SJ, Jackson SP. 1998. Components of the Ku-dependent nonhomologous end-joining pathway are involved in telomeric length maintenance and telomeric silencing. EMBO J 17: 1819-28.

43 Ajimura M, Leem SH, Ogawa H. 1993. Identification of new genes required for meiotic recombination in Saccharomyces cerevisiae. Genetics 133: 51-66.

44 Johzuka K, Ogawa H. 1995. Interaction of Mre11 and Rad50: two proteins required for DNA repair and meiosis-specific double-strand break formation in Saccharomyces cerevisiae. Genetics 139: 1521-32. 
45 Game JC, Zamb TJ, Braun RJ, Resnick M, et al. 1980. The Role of Radiation (rad) Genes in Meiotic Recombination in Yeast. Genetics 94: 5168.

46 Moreau S, Ferguson JR, Symington LS. 1999. The nuclease activity of Mre11 is required for meiosis but not for mating type switching, end joining, or telomere maintenance. Mol Cell Biol 19: 556-66.

47 Ritchie KB, Petes TD. 2000. The Mre11p/Rad50p/Xrs2p complex and the Tel1 $p$ function in a single pathway for telomere maintenance in yeast. Genetics 155: 475-9.

48 Ciapponi L, Cenci G, Ducau J, Flores C, et al. 2004. The Drosophila Mre11/Rad50 complex is required to prevent both telomeric fusion and chromosome breakage. Curr Biol 14: 1360-6.

49 Le S, Moore JK, Haber JE, Greider CW. 1999. RAD50 and RAD51 define two pathways that collaborate to maintain telomeres in the absence of telomerase. Genetics 152: 143-52.

$50 \quad$ Pan Q, Petit-Frere C, Lahdesmaki A, Gregorek H, et al. 2002. Alternative end joining during switch recombination in patients with ataxia-telangiectasia. Eur J Immunol 32: 1300-8.

51 Lahdesmaki A, Taylor AM, Chrzanowska KH, Pan-Hammarstrom Q. 2004. Delineation of the - complex in class switch recombination.J Biol Chem 279: 16479-87.

52 Dinkelmann M, Spehalski E, Stoneham T, Buis J, et al. 2009. Multiple functions of MRN in end-joining pathways during isotype class switching. Nat Struct Mol Biol 16: 808-13.

53 Kracker S, Bergmann Y, Demuth I, Frappart PO, et al. 2005. Nibrin functions in Ig class-switch recombination. Proc Natl Acad Sci U S A 102: 1584-9.

54 Roth S, Rottach A, Lotz-Havla AS, Laux V, et al. 2014. Rad50-CARD9 interactions link cytosolic DNA sensing to IL-1beta production. Nat Immunol.

55 Kondo T, Kobayashi J, Saitoh T, Maruyama K, et al. 2013. DNA damage sensor MRE11 recognizes cytosolic double-stranded DNA and induces type I interferon by regulating STING trafficking. Proc Natl Acad Sci U S A 110: 2969-74.

56 Nelms BE, Maser RS, MacKay JF, Lagally MG, et al. 1998. In situ visualization of DNA double-strand break repair in human fibroblasts. Science 280: 590-2.

57 de Jager M, van Noort J, van Gent DC, Dekker C, et al. 2001. Human Rad50/Mre11 is a flexible complex that can tether DNA ends. Mol Cell 8: 1129-35.

58 Hopfner KP, Craig L, Moncalian G, Zinkel RA, et al. 2002. The Rad50 zinc-hook is a structure joining Mre11 complexes in DNA recombination and repair. Nature 418: 562-6.

59 Wiltzius JJ, Hohl M, Fleming JC, Petrini JH. 2005. The Rad50 hook domain is a critical determinant of Mre11 complex functions. Nat Struct Mol Biol 12: 403-7.

60 de Jager M, Wyman C, van Gent DC, Kanaar R. 2002. DNA end-binding specificity of human Rad50/Mre11 is influenced by ATP. Nucleic Acids Res 30: 4425-31. 
61 Reis CC, Batista S, Ferreira MG. 2012. The fission yeast MRN complex tethers dysfunctional telomeres for NHEJ repair. EMBO J 31: 4576-86.

62 Taylor EM, Cecillon SM, Bonis A, Chapman JR, et al. 2010. The Mre11/Rad50/Nbs1 complex functions in resection-based DNA end joining in Xenopus laevis. Nucleic Acids Res 38: 441-54.

63 Falck J, Coates J, Jackson SP. 2005. Conserved modes of recruitment of ATM, ATR and DNA-PKcs to sites of DNA damage. Nature 434: 605-11.

64 Lee JH, Paull TT. 2005. ATM activation by DNA double-strand breaks through the Mre11-Rad50-Nbs1 complex. Science 308: 551-4.

65 Herdendorf TJ, Albrecht DW, Benkovic SJ, Nelson SW. 2011.

Biochemical characterization of bacteriophage T4 Mre11-Rad50 complex. J Biol Chem 286: 2382-92.

66 Connelly JC, Kirkham LA, Leach DR. 1998. The SbcCD nuclease of Escherichia coli is a structural maintenance of chromosomes (SMC) family protein that cleaves hairpin DNA. Proc Natl Acad Sci U S A 95: 7969-74.

67 Hopfner KP, Karcher A, Shin D, Fairley C, et al. 2000. Mre11 and Rad50 from Pyrococcus furiosus: cloning and biochemical characterization reveal an evolutionarily conserved multiprotein machine. J Bacteriol 182: 6036-41.

68 Paull TT, Gellert M. 1998. The 3' to 5' exonuclease activity of Mre 11 facilitates repair of DNA double-strand breaks. Mol Cell 1: 969-79.

69 Balestrini A, Ristic D, Dionne I, Liu XZ, et al. 2013. The Ku heterodimer and the metabolism of single-ended DNA double-strand breaks. Cell Rep 3: $2033-45$.

70 Sun J, Lee KJ, Davis AJ, Chen DJ. 2012. Human Ku70/80 protein blocks exonuclease 1-mediated DNA resection in the presence of human Mre11 or Mre11/Rad50 protein complex. J Biol Chem 287: 4936-45.

71 Langerak P, Mejia-Ramirez E, Limbo O, Russell P. 2011. Release of Ku and MRN from DNA ends by Mre11 nuclease activity and Ctp1 is required for homologous recombination repair of double-strand breaks. PLoS Genet 7: e1002271.

72 Schlacher K, Christ N, Siaud N, Egashira A, et al. 2011. Double-strand break repair-independent role for BRCA2 in blocking stalled replication fork degradation by MRE11. Cell 145: 529-42.

73 Ying S, Hamdy FC, Helleday T. 2012. Mre11-dependent degradation of stalled DNA replication forks is prevented by BRCA2 and PARP1. Cancer Res 72: 2814-21.

74 Hopkins BB, Paull TT. 2008. The P. furiosus mre11/rad50 complex promotes 5' strand resection at a DNA double-strand break. Cell 135: 250-60.

75 Connelly JC, de Leau ES, Leach DR. 2003. Nucleolytic processing of a protein-bound DNA end by the E. coli SbcCD (MR) complex. DNA Repair (Amst) 2: 795-807.

76 Paull TT, Gellert M. 1999. Nbs1 potentiates ATP-driven DNA unwinding and endonuclease cleavage by the Mre11/Rad50 complex. Genes Dev 13: 1276-88.

77 Cejka P, Cannavo E, Polaczek P, Masuda-Sasa T, et al. 2010. DNA end resection by Dna2-Sgs1-RPA and its stimulation by Top3-Rmi1 and Mre11-Rad50-Xrs2. Nature 467: 112-6. 
78 Liao S, Guay C, Toczylowski T, Yan H. 2012. Analysis of MRE11's function in the 5'-->3' processing of DNA double-strand breaks. Nucleic Acids Res 40: 4496-506.

79 Mimitou EP, Symington LS. 2008. Sae2, Exo1 and Sgs1 collaborate in DNA double-strand break processing. Nature 455: 770-4.

80 Zhu Z, Chung WH, Shim EY, Lee SE, et al. 2008. Sgs1 Helicase and Two Nucleases Dna2 and Exo1 Resect DNA Double-Strand Break Ends. Cell 134: 981-94.

81 Sartori AA, Lukas C, Coates J, Mistrik M, et al. 2007. Human CtIP promotes DNA end resection. Nature 450: 509-14.

82 Limbo 0, Chahwan C, Yamada Y, de Bruin RA, et al. 2007. Ctp1 is a cellcycle-regulated protein that functions with Mre11 complex to control double-strand break repair by homologous recombination. Mol Cell 28: 134-46.

83 Lengsfeld BM, Rattray AJ, Bhaskara V, Ghirlando R, et al. 2007. Sae2 is an endonuclease that processes hairpin DNA cooperatively with the Mre11/Rad50/Xrs2 complex. Mol Cell 28: 638-51.

84 Clerici M, Mantiero D, Lucchini G, Longhese MP. 2005. The Saccharomyces cerevisiae Sae2 protein promotes resection and bridging of double strand break ends. J Biol Chem 280: 38631-8.

85 Wang H, Li Y, Truong LN, Shi LZ, et al. 2014. CtIP Maintains Stability at Common Fragile Sites and Inverted Repeats by End ResectionIndependent Endonuclease Activity. Mol Cell.

86 Makharashvili N, Tubbs AT, Yang SH, Wang H, et al. 2014. Catalytic and Noncatalytic Roles of the CtIP Endonuclease in Double-Strand Break End Resection. Mol Cell.

87 Shibata A, Moiani D, Arvai AS, Perry J, et al. 2013. DNA Double-Strand Break Repair Pathway Choice Is Directed by Distinct MRE11 Nuclease Activities. Mol Cell.

88 Garcia V, Phelps SEL, Gray S, Neale MJ. 2011. Bidirectional resection of DNA double-strand breaks by Mre11 and Exo1. Nature 479: 241-4.

89 Eykelenboom JK, Blackwood JK, Okely E, Leach DR. 2008. SbcCD causes a double-strand break at a DNA palindrome in the Escherichia coli chromosome. Mol Cell 29: 644-51.

90 Ghosal G, Muniyappa K. 2005. Saccharomyces cerevisiae Mre11 is a high-affinity G4 DNA-binding protein and a G-rich DNA-specific endonuclease: implications for replication of telomeric DNA. Nucleic Acids Res 33: 4692-703.

91 Neale MJ, Pan J, Keeney S. 2005. Endonucleolytic processing of covalent protein-linked DNA double-strand breaks. Nature 436: 1053-7.

92 Sacho EJ, Maizels N. 2011. DNA repair factor MRE11/RAD50 cleaves 3'phosphotyrosyl bonds and resects DNA to repair damage caused by topoisomerase 1 poisons. J Biol Chem 286: 44945-51.

93 Hartsuiker E, Neale MJ, Carr AM. 2009. Distinct requirements for the Rad32(Mre11) nuclease and Ctp1(CtIP) in the removal of covalently bound topoisomerase I and II from DNA. Mol Cell 33: 117-23.

94 Liu C, Pouliot JJ, Nash HA. 2002. Repair of topoisomerase I covalent complexes in the absence of the tyrosyl-DNA phosphodiesterase Tdp1. Proc Natl Acad Sci U S A 99: 14970-5. 
95 Deng C, Brown JA, You D, Brown JM. 2005. Multiple endonucleases function to repair covalent topoisomerase I complexes in Saccharomyces cerevisiae. Genetics 170: 591-600.

96 Milne GT, Jin S, Shannon KB, Weaver DT. 1996. Mutations in two Ku homologs define a DNA end-joining repair pathway in Saccharomyces cerevisiae. Mol Cell Biol 16: 4189-98.

97 Hopfner KP, Karcher A, Shin DS, Craig L, et al. 2000. Structural biology of Rad50 ATPase: ATP-driven conformational control in DNA doublestrand break repair and the ABC-ATPase superfamily. Cell 101: 789-800.

98 Hopfner KP, Karcher A, Craig L, Woo TT, et al. 2001. Structural biochemistry and interaction architecture of the DNA double-strand break repair Mre11 nuclease and Rad50-ATPase. Cell 105: 473-85.

99 de Jager M, Trujillo KM, Sung P, Hopfner KP, et al. 2004. Differential arrangements of conserved building blocks among homologs of the Rad50/Mre11 DNA repair protein complex. J Mol Biol 339: 937-49.

100 Lammens K, Bemeleit DJ, Mockel C, Clausing E, et al. 2011. The Mre11:Rad50 structure shows an ATP-dependent molecular clamp in DNA double-strand break repair. Cell 145: 54-66.

101 Mockel C, Lammens K, Schele A, Hopfner KP. 2012. ATP driven structural changes of the bacterial Mre11:Rad50 catalytic head complex. Nucleic Acids Res 40: 914-27.

102 Schiller CB, Lammens K, Guerini I, Coordes B, et al. 2012. Structure of Mre11-Nbs1 complex yields insights into ataxia-telangiectasia-like disease mutations and DNA damage signaling. Nat Struct Mol Biol 19: 693-700.

103 Williams RS, Moncalian G, Williams JS, Yamada Y, et al. 2008. Mre11 dimers coordinate DNA end bridging and nuclease processing in doublestrand-break repair. Cell 135: 97-109.

104 Williams RS, Dodson GE, Limbo O, Yamada Y, et al. 2009. Nbs1 flexibly tethers Ctp1 and Mre11-Rad50 to coordinate DNA double-strand break processing and repair. Cell 139: 87-99.

105 Lim HS, Kim JS, Park YB, Gwon GH, et al. 2011. Crystal structure of the Mre11-Rad50-ATPgammaS complex: understanding the interplay between Mre11 and Rad50. Genes Dev 25: 1091-104.

106 Park YB, Chae J, Kim YC, Cho Y. 2011. Crystal structure of human Mre11: understanding tumorigenic mutations. Structure 19: 1591-602.

107 Moreno-Herrero F, de Jager M, Dekker NH, Kanaar R, et al. 2005. Mesoscale conformational changes in the DNA-repair complex Rad50/Mre11/Nbs1 upon binding DNA. Nature 437: 440-3.

108 Lloyd J, Chapman JR, Clapperton JA, Haire LF, et al. 2009. A supramodular FHA/BRCT-repeat architecture mediates Nbs1 adaptor function in response to DNA damage. Cell 139: 100-11.

109 Das D, Moiani D, Axelrod HL, Miller MD, et al. 2010. Crystal structure of the first eubacterial Mre11 nuclease reveals novel features that may discriminate substrates during DNA repair. J Mol Biol 397: 647-63.

110 Williams GJ, Williams RS, Williams JS, Moncalian G, et al. 2011. ABC ATPase signature helices in Rad50 link nucleotide state to Mre11 interface for DNA repair. Nat Struct Mol Biol 18: 423-31. 
111 Albrecht DW, Herdendorf TJ, Nelson SW. 2012. Disruption of the bacteriophage T4 Mre11 dimer interface reveals a two-state mechanism for exonuclease activity. J Biol Chem 287: 31371-81.

112 Majka J, Alford B, Ausio J, Finn RM, et al. 2012. ATP hydrolysis by RAD50 protein switches MRE11 enzyme from endonuclease to exonuclease. J Biol Chem 287: 2328-41.

113 Cannon B, Kuhnlein J, Yang SH, Cheng A, et al. 2013. Visualization of local DNA unwinding by Mre11/Rad50/Nbs1 using single-molecule FRET. Proc Natl Acad Sci U S A 110: 18868-73.

114 Hohl M, Kwon Y, Galvan SM, Xue X, et al. 2011. The Rad50 coiled-coil domain is indispensable for Mre11 complex functions. Nat Struct Mol Biol 18: 1124-31.

115 Roset R, Inagaki A, Hohl M, Brenet F, et al. 2014. The Rad50 hook domain regulates DNA damage signaling and tumorigenesis. Genes Dev 28: 451-62.

116 Lee JH, Mand MR, Deshpande RA, Kinoshita E, et al. 2013. Ataxia telangiectasia-mutated (ATM) kinase activity is regulated by ATP-driven conformational changes in the Mre11/Rad50/Nbs1 (MRN) complex. J Biol Chem 288: 12840-51.

117 Tsukamoto Y, Mitsuoka C, Terasawa M, Ogawa H, et al. 2005. Xrs2p regulates Mre11p translocation to the nucleus and plays a role in telomere elongation and meiotic recombination. Mol Biol Cell 16: 597608.

118 Stracker TH, Morales M, Couto SS, Hussein H, et al. 2007. The carboxy terminus of NBS1 is required for induction of apoptosis by the MRE11 complex. Nature 447: 218-21.

119 Moncalian G, Lengsfeld B, Bhaskara V, Hopfner KP, et al. 2004. The rad50 signature motif: essential to ATP binding and biological function. $J$ Mol Biol 335: 937-51.

Figure Legends:

Fig. 1. Roles of the Mre11-Rad50-Nbs1 complex - coloured ovals marked M, R, $\mathbf{N}$ - in the DNA double-strand break response.

Shown in a simplified scheme, MRN (which has a stoichiometry of M2, R2 and N1 or N2) helps recruit ATM to the sites of the break, which upon activation phosphorylates hundreds of target proteins including histone $2 A X$. MRN is also a structural component at DNA ends and helps tether DNA ends, although the precise mode of this tethering function remains to be established. In conjunction with CtIP, MRN is involved in initial processing of DNA ends that can be repaired by mismatch mediated end joining and are substrates for long-range resection by Exo1 and DNA2 exonucleases prior to HDR. 


\section{Fig. 2. Structural model of the Mre11-Rad50-Nbs1.}

Two Rad50 subunits (yellow/yellow-orange) associate with an Mre11 dimer (light/dark blue). One (as shown, magenta) or possibly two Nbs1 polypeptides bind to Mre11 and confer protein interactions to ATM and other DNA damage response and repair proteins. Parts of the model are derived from crystal structures $([58,101,104,105,108])$ while the long coiled-coil tails are modeled. Experimentallydetermined structures are shown for the hook (in the structurally-derived complex with a hook from another coiled-coil [58]), for the "open" conformation of the Mre11 nuclease dimer in complex with the Rad50 NBD in the absence of ATP [100], and for the corresponding closed conformation with two ATPs (magenta spheres) bound to Rad50 $[101,105]$. In the open conformation, the Mre11 nuclease sites are exposed (red stars), while in the closed conformation they are partially blocked by Rad50. Thus, MR acts as an ATP-regulated switch or clamp.

Fig. 3. Simplified Model for the proposed ATP-regulated functional switch of the MRN complex in DSB repair. In the "closed" ATP-bound state, the nucleotide binding domains (NBDs) of Rad50 partially block the Mre11 nuclease (Nuc) and the MRN complex promotes DNA tethering and ATM activation. The way MRN binds DNA in this state is still unclear. In the "open" state, after ATP hydrolysis by Rad50, the Mre11 nuclease sites are exposed and can bind and cleave DNA in DSB processing. The precise way the coiled-coil domains of Rad50 interact or form supramolecular aggregates in different functional states is unclear and not explicitly depicted. 

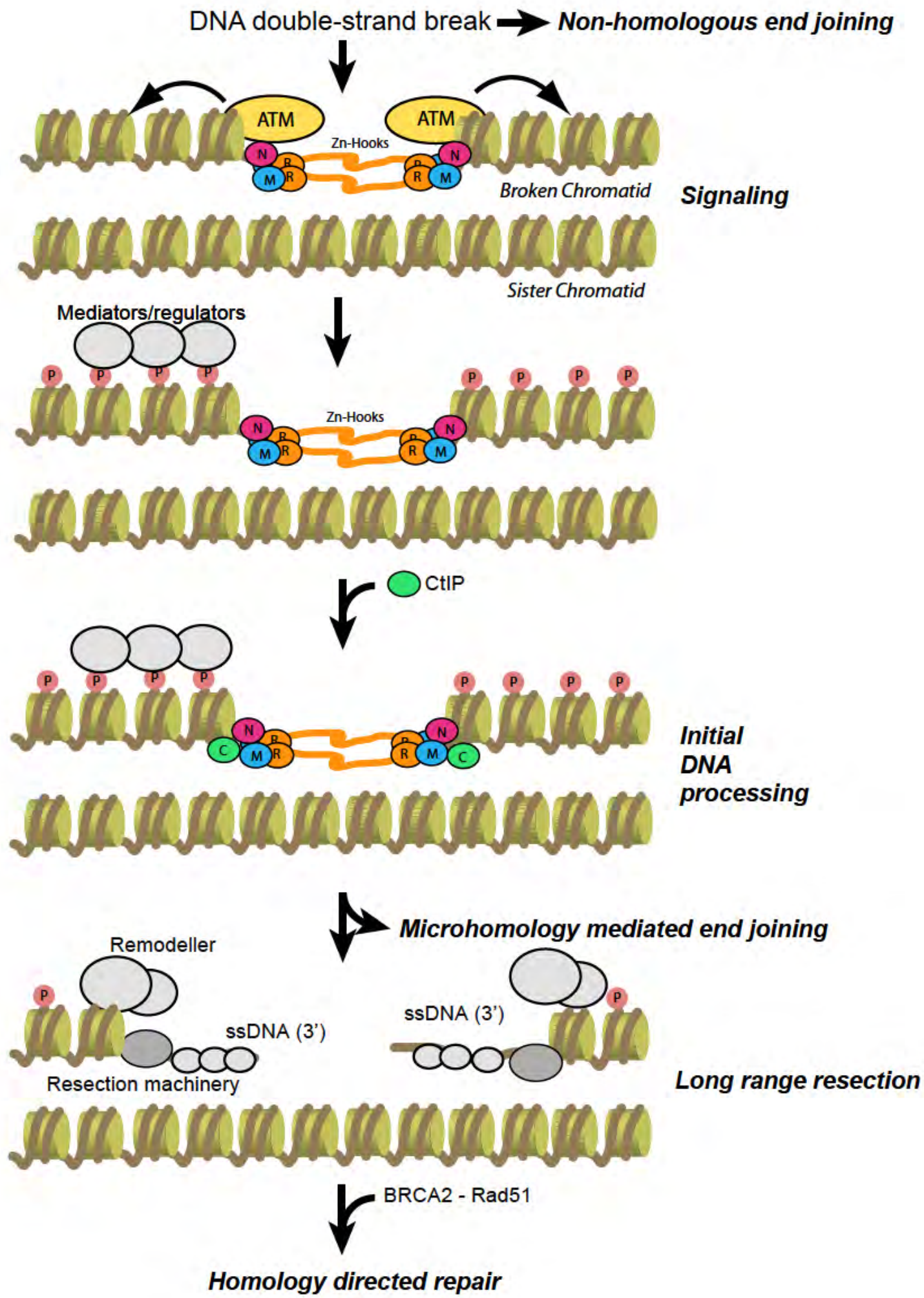


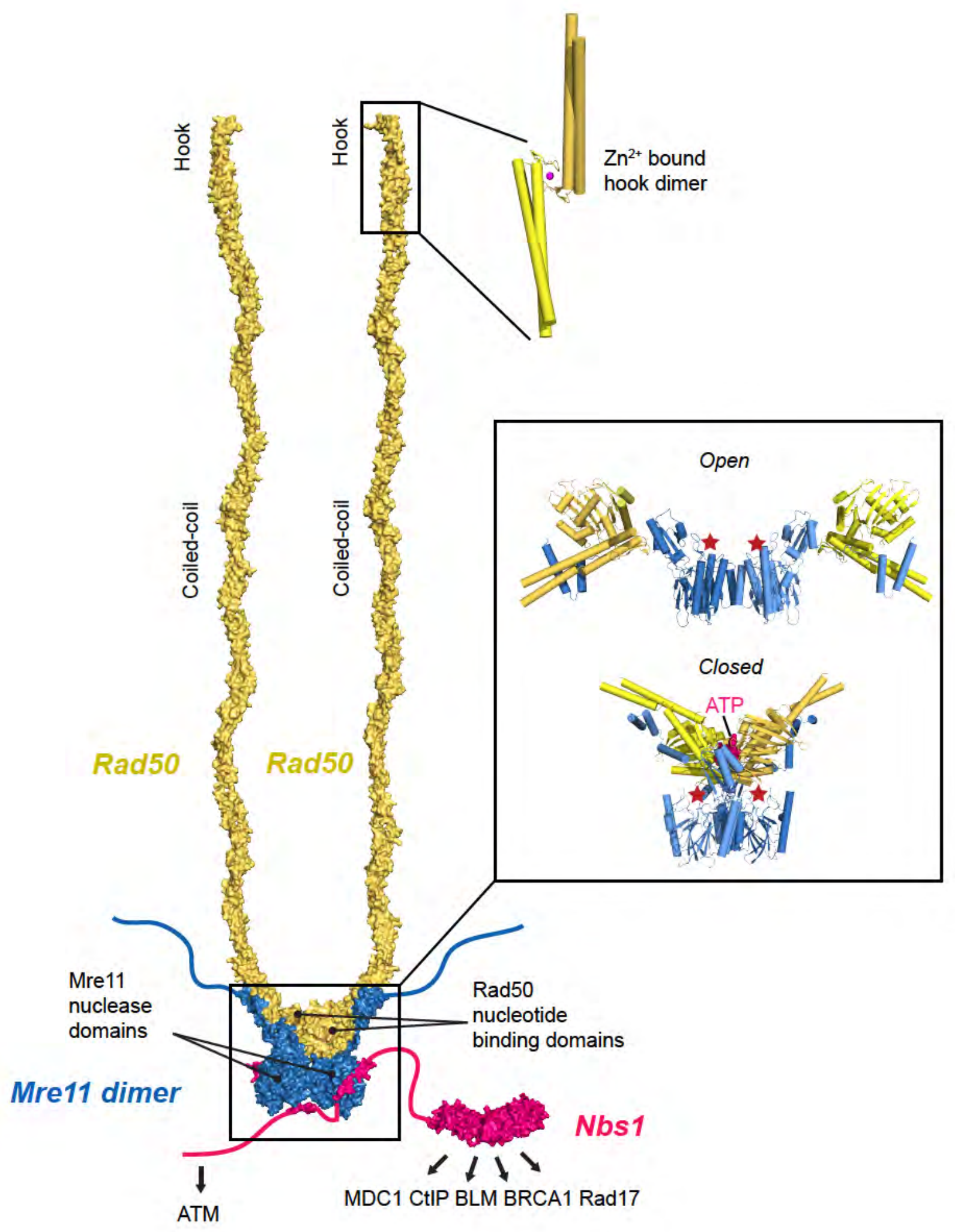




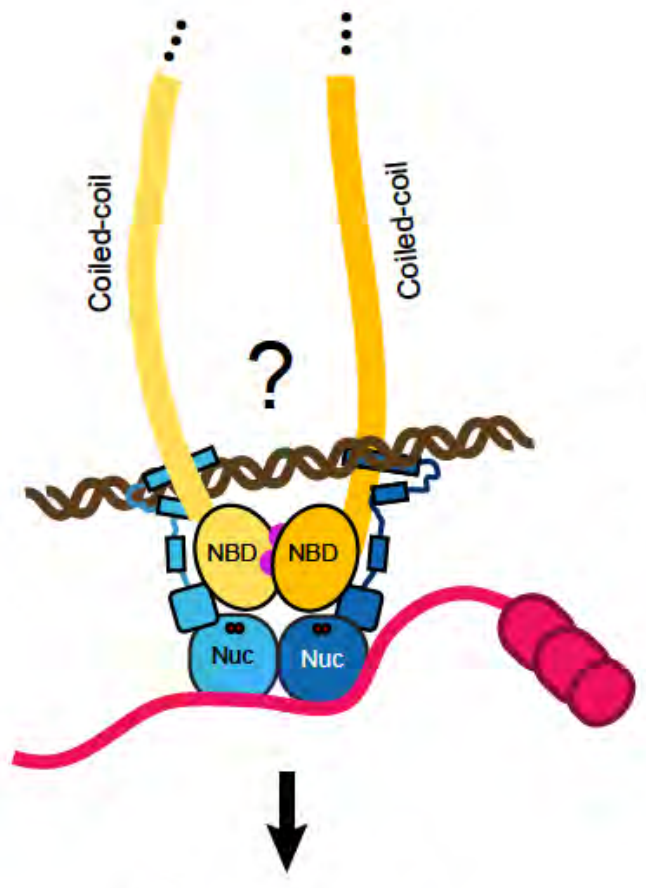

ATM activation
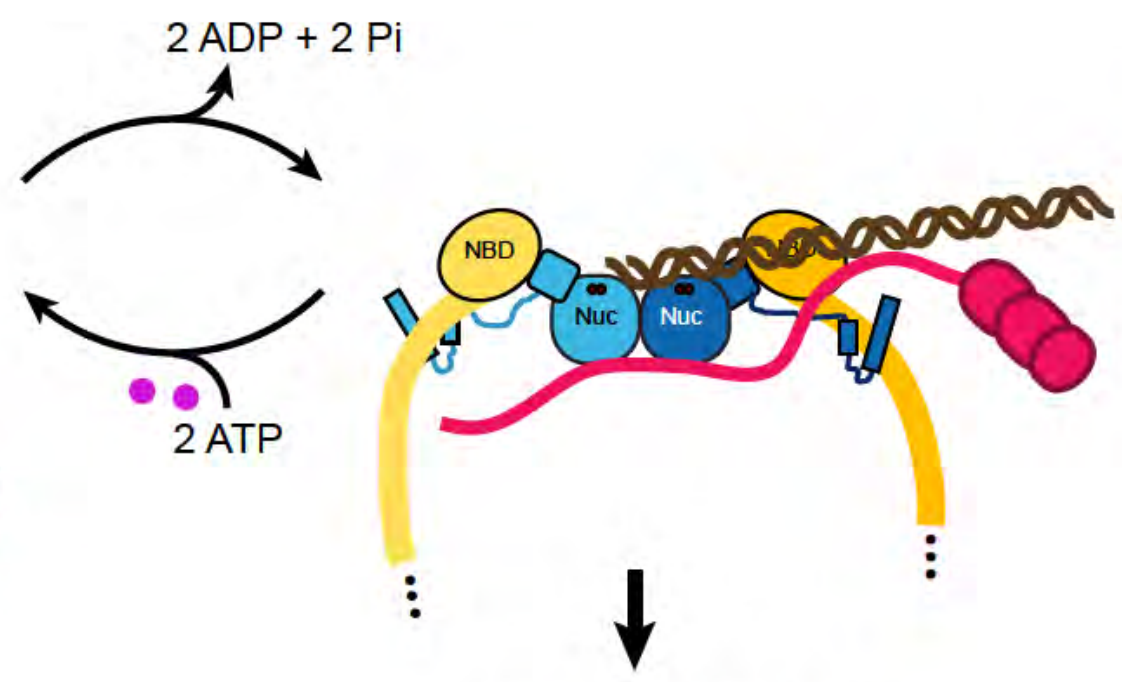

DNA processing

DNA tethering 